\title{
BMJ Global Health Building back fairer in public health policy requires collective action with and for the most vulnerable in society
}

\author{
Lucia D'Ambruoso (D) , ${ }^{1}$ Pamela Abbott (D) , ${ }^{2}$ Agnes Binagwaho (1) ${ }^{3}$
}

To cite: D'Ambruoso L, Abbott P, Binagwaho A. Building back fairer in public health policy requires collective action with and for the most vulnerable in society. BMJ Global Health 2021;6:e005555. doi:10.1136/ bmjgh-2021-005555

Received 28 February 2021 Revised 2 March 2021 Accepted 3 March 2021
(A) Check for updates

(C) Author(s) (or their employer(s)) 2021. Re-use permitted under CC BY-NC. No commercial re-use. See rights and permissions. Published by BMJ.

${ }^{1}$ Aberdeen Centre for Health Data Science, Institute of Applied Health Sciences, School of Medicine, Medical Sciences and Nutrition, University of Aberdeen, Aberdeen, UK ${ }^{2}$ Centre for Global Development, School of Education, University of Aberdeen, Aberdeen, UK ${ }^{3}$ Office of the Vice Chancellor, University of Global Health Equity, Kigali, Rwanda

Correspondence to Dr Lucia D'Ambruoso lucia.dambruoso@abdn.ac.uk

\section{INTRODUCTION}

During the COVID-19 pandemic, politicians have repeatedly used rhetoric that 'we' (they) have to 'follow the science', justifying their actions as rational. Political science provides a more complex picture, in which public policy is shaped by a 'competition for ideas', with problems raised and framed differently by different actors located within networks of power, interests and resources. ${ }^{1}$ From this perspective, it is possible to appreciate why alternative arguments get little attention.

In this commentary, we argue that community intelligence has not featured sufficiently in state responses to COVID-19, and that building resilient health systems with high-quality, timely care for all people, with and without COVID-19 must incorporate the voices of those most disproportionately affected as legitimate sources of knowledge and action.

\section{WHAT IS EVIDENCE AND HOW IS IT MADE?}

COVID-19 reflects and exacerbates existing social inequalities. Within and between countries, statistical data reveal stark differentials in mortality among minority ethnic communities and in deprived areas. ${ }^{23}$ While vulnerability changes with the type of threat, poor and marginalised people are consistently disproportionately affected. Health inequalities have been extensively discussed, including in terms of social, political and commercial drivers. ${ }^{45}$ Despite the longevity and breadth of this work, it remains relatively uncommon to amplify the voices of those most directly affected.

A decade ago, sociologist Vicente Navarro pointed out the 'studious avoidance of the category of power' in research into the social determinants of health and that it is not inequalities that kill people, it is those who are responsible for inequalities who kill people. ${ }^{6}$
Summary box

The COVID-19 pandemic reveals how public policy is shaped by a 'competition for ideas', where problems are raised and framed differently by different actors located within hierarchies of power, networks and resources.

- Despite statistical data revealing inequalities in the distribution of burden and risk, it remains relatively uncommon to amplify the voices of those most directly affected.

- The pandemic has also revealed monopolies of knowledge production, with global burdens estimated by institutions in the global north developed through methodologies that lack transparency, this disempowers low-income and middle-income countries.

- In many so-called developed democracies, the responses to the pandemic have been inadequate with cutbacks to health and social services limited commitment to equity in leadership and poor governance, ensuring some issues make it onto policy agendas while others are suppressed.

- Building and maintaining equitable and resilient health systems reconciling COVID-19 with highquality, timely care for all people, with and without COVID-19, and particularly vulnerable groups requires community voices to be regarded as critical sources of evidence for policy learning.

This critique illuminates our partial understanding of vulnerability: limited to statistical representations of 'who sinks and who swims', and failing to account for 'who is throwing who into the river and why'. ${ }^{6}$

Nevertheless, the pandemic is forcing renewed acknowledgement of power as the fundamental driver of health inequalities. There have been new calls: to reclaim comprehensive public health rooted in public interest, focused on cooperation, participatory decision-making, and action that supports dignity, rights and social justice ${ }^{7}$; to ensure that community empowerment focuses on systems and structural transformation ${ }^{8}$; and 
to build back fairer, highlighting the quality of governance, political culture and cutbacks to health and social services as key drivers of nation-state vulnerabilities. ${ }^{2}$

\section{WHO RAISES CONCERNS AND WHO RESPONDS?}

Despite these, the 'competition for ideas' remains a deeply uneven playing field. The pandemic has highlighted existing monopolies of knowledge production, with northern institutions such as the Institute for Health Metrics and Evaluation, supported by the Bill and Melinda Gates Foundation and The Lancet, criticised for a lack of transparency with practices that serve to distort public health data. ${ }^{9}$ Such knowledge hegemonies have serious implications: disenfranchising low-income and middle-income countries (LMICs) from their own data and diverting resources from building evidence infrastructure and information systems, the absence of which perpetuates externalised, non-transparent estimations.

The pandemic has also revealed that systems for translating evidence into policy and practice are inadequate. As alluded to above, political power ensures certain issues make it onto the policy agenda, while others are suppressed. This operates at many levels. Decisionmaking teams leading pandemic responses are overwhelmingly comprised of men. ${ }^{10}$ And, in a number of so-called advanced democracies that have failed in the COVID-19 response, there is a serious downward shift in the quality of governance, clear non-commitment to equity in health service delivery, and leaders' agendas are focused on their own self-interest. ${ }^{11} 12$

\section{(EVIDENCE ON) HEALTH FOR ALL?}

COVID-19 has demanded substantial and rapid reorganisation of healthcare systems. While the focus has been on suppression and hospital care for patients with COVID-19, a COVID-focused health and social care system has deeply negative implications for the health and well-being of all population groups by limiting access to medical care for patients with chronic illness and the population at large. There is an urgent need to reconcile COVID-19 with high-quality, timely care for all people with and without COVID-19 and particularly for vulnerable groups.

COVID-19 clusters and interacts with pre-existing conditions, most notably non-communicable diseases (NCDs) such as diabetes and obesity. NCDs are a looming disaster, especially in LMICs. Heart disease, cancer, respiratory disorders and diabetes account for 15 million premature deaths worldwide, over $80 \%$ of which occur in LMICs. Recent debates have reframed NCDs from an equity perspective, with an expanded set of conditions including mental disorders and injuries 'NCDIs' as a phenomenon of the world's poor. ${ }^{13}$ This work has revealed disproportionate impacts on children and young adults in LMICs: who get sicker earlier and for longer. One in 10 children globally have a mental health problem, and $70 \%$ do not have interventions at a sufficiently early age. ${ }^{14}$
As with COVID-19, NCDIs are socially patterned. And as with many of the less successful responses to COVID19 , policy responses for NCDs generally promote individual behaviour change, neglecting structural, social, environmental and commercial determinants that drive and maintain vulnerability. These are social issues with social, as opposed to individual, causes and can only be solved with collective action. Enabling community voices to inform policy therefore needs to address structural determinants, advancing disease prevention and control cognisant of structural determinants as an essential perspective.

\section{THE FUTURE IS COLLECTIVE}

Past pandemic experience indicates that community mobilisation is critical for effective mitigation. ${ }^{15}$ Engaging communities is recommended by the WHO as a key pillar of COVID-19 country responses to prevent infection and slow transmission, be prepared for future outbreaks and respond to rapidly changing situations. ${ }^{16}$ Despite this, community intelligence has not featured highly in state responses. ${ }^{17}$ Negotiating the location of this knowledge in state responses requires an openness to diverse forms of knowledge to operationalise the concept and involve communities in responses.

Community mobilisation alone is insufficient, however. To address the structural conditions that necessitate empowerment of marginalised groups, engaging with multiple stakeholders: patients and communities, practitioners, policy makers and academics in evidencegeneration and utilisation is necessary. ${ }^{18}$ Indeed, coproduction is being described as 'the future', defined as "the sharing of power, with stakeholders and researchers working together to develop the agenda, design and implement the research, and interpret, disseminate, and implement the findings". ${ }^{19}$ Sensitivity to power, and commitment to building relationships and trust, is also critical.

Many countries that have managed COVID-19 well have not adopted technocratic, individualised, top-down responses as has been the case in many Western countries. In Rwanda, a system based on trust and solidarity has been critical. ${ }^{20}$ Here, a community-based preventative approach, largely driven by centrally organised, and locally recruited and monitored community health workers (CHWs) led to the steepest reductions in child and maternal mortality ever recorded. ${ }^{21}{ }^{22}$ Among other things, CHWs manage uncomplicated malaria, diarrhoea and pneumonia in communities; ensure health promotion and disease prevention; and collect community health information. As essential links between communities and formal health systems, CHWs have built trust among communities and the formal health system. ${ }^{20}$ In the face of the pandemic, this has built a foundation of resilience.

Digital mobilisation has also gained prominence, with collective, community-led responses, working with and/ 
or circumventing formal decision-making structures. Prior to and during the pandemic, practices of citizens convening and participating in discussions using new media and communication platforms have been documented. Across Somalia, Ethiopia, Sudan, Uganda, Tanzania, Kenya, South Africa, Rwanda and Zimbabwe, varied roles are played by WhatsApp groups convening citizens for collective action. ${ }^{23}{ }^{24}$ Digital mobilisation has highlighted important implications for breaking free of Western frames of reference that may limit engagement.

\section{CONCLUSION}

Ultimately, you cannot fight what you cannot see: if we fail to understand the fundamental root causes of health inequalities, then we remain blind as to how to address them. While debates over centuries have advocated for attention to the structural determinants of chronic illness, how to progress understanding of and attention to structural and system transformation is less well understood.

Equitable and resilient health systems cannot be built during a crisis. Instead, we must be prepared to face crises by building and maintaining equitable and resilient health systems in ordinary times, recognising mutual interdependencies and shared vulnerabilities as part of a social justice approach. Legitimising community voices in processes of social and political transformation, building wider cooperative relationships and mutual understanding supports the building of trust.

Building and maintaining equitable and resilient health systems reconciling COVID-19 with high-quality, timely care for all people with and without COVID-19 and particularly vulnerable groups requires community voices to be regarded as legitimate sources of evidence and action within formal systems and governance processes to support policy learning suitable for contexts of uncertainty and complexity and to identify and address health inequalities.

If public policy is a 'competition for ideas', where issues are raised by a range of stakeholders located within networks of power, interests and resources, then collective sensemaking holds promise to support real-time policy learning between preventive and curative care, authorities and communities. Strengthening the capacities of multiple stakeholders in the mobilisation of knowledge and action on health inequalities in everyday contexts and interactions will enable responses to be driven by the interests, experiences and vulnerabilities of the majority, not the vested interests of the few.

Twitter Lucia D'Ambruoso @luciadambruoso, Pamela Abbott @pamelaabbott271 and Agnes Binagwaho @agnesbinagwaho

Acknowledgements We acknowledge the University of Aberdeen for supporting the project.

Contributors The authors held a joint discussion through which the main ideas were developed. LD then prepared a draft manuscript. All authors contributed critically to the draft and approved the final version.
Funding This paper results from a collaboration between the authors in a project coordinated by the University of Aberdeen and University for Global Health Equity.

Competing interests None declared.

Patient consent for publication Not required.

Provenance and peer review Not commissioned; internally peer reviewed.

Data availability statement There are no data in this work.

Open access This is an open access article distributed in accordance with the Creative Commons Attribution Non Commercial (CC BY-NC 4.0) license, which permits others to distribute, remix, adapt, build upon this work non-commercially, and license their derivative works on different terms, provided the original work is properly cited, appropriate credit is given, any changes made indicated, and the use is non-commercial. See: http://creativecommons.org/licenses/by-nc/4.0/.

\section{ORCID iDs}

Lucia D'Ambruoso http://orcid.org/0000-0002-8505-3368

Pamela Abbott http://orcid.org/0000-0002-5013-343X

Agnes Binagwaho http://orcid.org/0000-0002-6779-3151

\section{REFERENCES}

1 Cairney P. Understanding Public Policy - Paul Cairney - Macmillan International Higher Education. Red Globe Press, 2019. Available: https://www.macmillanihe.com/page/detail/Understanding-PublicPolicy/?K=9781137545183 [Accessed 17 Dec 2020].

2 Marmot M, Allen J, Goldblatt P. Build back fairer: the COVID-19 Marmot review. The pandemic, socioeconomic and health inequalities in England. London, 2020. Available: http://www.inst ituteofhealthequity.org/about-our-work/latest-updates-from-theinstitute/build-back-fairer [Accessed 17 Dec 2020].

3 Macharia PM, Joseph NK, Okiro EA. A vulnerability index for COVID-19: spatial analysis at the subnational level in Kenya. BMJ Glob Heal 2020;5:e003014.

4 DHSS. Inequalities in Health: Report of a Research Working Group. London: Research Working Group, 1980. https://www.sochealth.co. uk/national-health-service/public-health-and-wellbeing/poverty-andinequality/the-black-report-1980/

5 WHO. Closing the Gap in a Generation Health Equity through Action on the. Geneva: Social Determinants of Health, 2008.

6 Navarro V. What we mean by social determinants of health. Int J Health Serv 2009;39:423-41.

7 Loewenson R, Accoe K, Bajpai N, et al. Reclaiming comprehensive public health. BMJ Glob Health 2020;5:e003886.

8 Popay J, Whitehead M, Ponsford R, et al. Power, control, communities and health inequalities $\mathrm{I}$ : theories, concepts and analytical frameworks. Health Promot Int 2020. doi:10.1093/heapro/ daaa133. [Epub ahead of print: 31 Dec 2020].

9 Schwab T. Are Bill Gates's Billions Distorting Public Health Data? The Nation, 2020. Available: https://www.thenation.com/article/ society/gates-covid-data-ihme/ [Accessed 17 Dec 2020].

10 Dhatt R. Investing in civil society for better democracy and better health [blog]. BMJ, 2020. Available: https://blogs.bmj.com/bmj/ 2020/10/23/investing-in-civil-society-for-better-democracy-andbetter-health/?utm_source=twitter\&utm_medium=social\&utm_term= hootsuite\&utm_content=sme\&utm_campaign=usage [Accessed 17 Dec 2020].

11 Good Law Project. Fight for transparency - Good Law Project, 2020. Available: https://goodlawproject.org/case/fight-for-transparency/ [Accessed 20 Feb 2021].

12 Yamey G, Gonsalves G. Donald Trump: a political determinant of covid-19. BMJ 2020:369.

13 Bukhman G, Mocumbi AO, Atun R, et al. The Lancet NCDI poverty Commission: bridging a gap in universal health coverage for the poorest billion. Lancet 2020;396:991-1044.

14 Mental Health Foundation. Mental health in children and young people, 2020. Available: https://www.mentalhealth.org.uk/a-to-z/c/ children-and-young-people [Accessed 17 Dec 2020].

15 Dhillon RS, Kelly JD. Community trust and the Ebola endgame. $N$ Engl J Med 2015;373:787-9.

16 WHO. Risk communication and community engagement (RCCE) action plan guidance COVID-19 preparedness and response. Geneva: WHO, 2020. https://www.who.int/publications/i/item/riskcommunication-and-community-engagement-(rcce)-action-planguidance

17 Gilmore B, Ndejjo R, Tchetchia A, et al. Community engagement for COVID-19 prevention and control: a rapid evidence synthesis. BMJ Glob Health 2020;5:e003188. 
18 Thamarangsi T. The "triangle that moves the mountain" and Thai alcohol policy development: four case studies. Contemp Drug Probl 2009;36:245-81.

19 Redman S, Greenhalgh T, Adedokun L, et al. Co-production of knowledge: the future. BMJ 2021;372:n434.

20 Cahan EM. Rwanda's secret weapon against covid-19: trust. BMJ 2020;371:m4720.

21 Global Governance Program. Health A Political Choice Act Now Together. In: Kickbusch I, Kirton J, eds. Geneva: WHO, 2020.
22 Amoroso CL, Nisingizwe MP, Rouleau D, et al. Next wave of interventions to reduce under-five mortality in Rwanda: a crosssectional analysis of demographic and health survey data. BMC Pediatr 2018;18:1-11.

23 Srinivasan S, Diepeveen S, Karekwaivanane G. Rethinking publics in Africa in a digital age. J East African Stud 2019;13:2-17.

24 van Ryneveld M, Whyle E, Brady L. What is COVID-19 teaching us about community health systems? A reflection from a rapid Community-Led mutual aid response in Cape town, South Africa. Int $J$ Heal Policy Manag 2020;2020:1-4. 